\title{
Strategi Pemasaran Menyambut Pranatan Baru Pariwisata Yogyakarta (Studi Kasus Hotel Cabin Sutomo)
}

\author{
Sugiyah $^{1}$, Kartika Yuliantari ${ }^{2}$, Nurhidayati ${ }^{3}$, Dwiyatmoko Puji Widodo ${ }^{4}$ \\ 1,2,3,4 Universitas Bina Sarana Informatika \\ J1. Kramat Raya No 98, Senen, Jakarta Pusat \\ e-mail: ${ }^{1}$ sugiyah.sgy@bsi.ac.id, ${ }^{2}$ kartika.kkj@bsi.ac.id, ${ }^{3}$ nurhidayati.nht@bsi.ac.id, \\ ${ }^{4}$ dwiyatmoko.dpw@bsi.ac.id
}

\begin{abstract}
Informasi Artikel
Diterima: 08-06-2021

Direvisi: 19-07-2021

Disetujui: 22-07-2021

Abstrak

Pariwisata, khususnya hotel merupakan salah satu sektor yang sangat merasakan dampak dari pandemi covic-19. Untuk mendorong percepatan pemulihan ekonomi sektor pariwisata, khususnya hotel, diperlukan regulasi yang dapat memperkuat perubahan ini, baik regulasi dari pemerintan pusat maupun daerah yang dapat mendorong perhotelan kembali bergairah mengacu pada protokol kesehatan. Tujuan dari penelitian ini untuk mengkaji strategi pemasaran Hotel Cabin Sutomo yang berpedoman pada pranata baru pariwisata Yogyakarta. Metode pengumpulan yang dilakukan menggunakan wawancara dengan supervisor dan bagian front office dan metode dokumentasi. Metode analisa pada penelitian ini adalah analisa deskriptif. Hasil penelitian menjelaskan adanya Pergub Nomor 48 tahun 2020 Pemerintah D.I. Yogyakarta tentang Pedoman Penyusunan, Panduan Pelaksanaan Kegiatan Pelayanan Publik dan Perekonomian Masyarakat di Daerah Istimewa Yogyakarta dalam pencegahan dan pengendalian Covid-19 dan buku Pranatan Anyar Plesiran Jogya Panduan Adaptasi Kebiasaan Baru Pariwisata DIY, mendorong Hotel Cabin Sutomo untuk melakukan perubahan strategi pemasaran, melalui aspek produk jasa dan karyawan yang memperhatikan protokol kesehatan, harga dengan jargon new normal, meningkatkan promosi secara online (digital). Dengan Langkah tersebut tahun 2020 di masa pandemi mengalami penurunan penjualan kamar sebesar 22,7\% dibandingkan tahun 2019. Penurunan penjualan ini, Hotel Cabin masih terus dapat beroperasional tanpa melakukan pengurangan karyawan.
\end{abstract}

Kata Kunci: Strategi pemasaran, Pranata baru, Pariwisata

\begin{abstract}
Tourism, especially hotels, is one sector that has felt the impact of the COVID-19 pandemic. To accelerate the economic recovery of the tourism sector, especially hotels, regulations are needed that can strengthen this change, both regulations from the central and regional governments that can encourage hospitality to return to enthusiasm referring to health protocols. The purpose of this research is to examine the marketing strategy of Hotel Cabin Sutomo based on the new Yogyakarta tourism institutions. The method of collecting is using interviews with supervisors and the front office section of the supervisor and by means of documentation. The method of analysis in this research is descriptive analysis. The results of the study explain the existence of Governor Regulation Number 48 of 2020, the D.I. Government. Yogyakarta regarding Guidelines for Preparation, Guidelines for Implementation of Public Service Activities and Community Economics in the Special Region of Yogyakarta in the prevention and control of Covid-19 and the book Pranatan Anyar Plesiran Jogya, Guidelines for Adapting New Habits of Tourism DIY, encourage Hotel Cabin Sutomo to make changes to marketing strategies, through product aspects services and employees who pay attention to health protocols, prices with new normal jargon, increasing online (digital) promotions. With this measure in 2020 during the pandemic, room sales decreased by $22.7 \%$ compared to 2019. With this decline in sales, Hotel Cabin can still operate without reducing employees.
\end{abstract}

Keywords: Marketing strategy, New institutions, Tourism

\section{Pendahuluan}

Sektor Pariwisata merupakan salah satu sektor yang terkena dampak cukup berat akibat pandemi covid-19. Jumlah pengunjung destinasi mengalami penurunan yang sangat signifikan baik wisatawan domestik, apalagi wisatawan asing. Kondisi ini tentunya berpengaruh juga pada sektor lainnya yang memiliki korelasi dengan pariwisata baik secara langsung maupun tidak langsung, seperti perhotelan, transportasi, bisnis kuliner, fashion dan 
para pelaku seni, keterpurukan ini yang akhirnya menjadi tekanan ekonomi yang cukup memberatkan para pelaku bisnis.

Sebagai bagian dari sektor Pariwisata tentunya merasakan dampak dari kondisi pandami ini. Strategi pemasaran yang dilakukan sebelum pandemi covid yang dapat dikatakan efektif dalam menarik minat tamu hotel, harus dilakukan penyesuaian di masa pandemi, sehingga dapat mengembalikan kepercayaan masyarakat terhadap sektor pariwisata khususnya pada hotel.

Yogyakarta sebagai salah satu daerah yang memiliki potensi sangat besar di bidang pariswisata,. Adanya destinasi peninggalan sejarah seperti Kraton Yogyakarta, Candi Prambanan dan keindahan alamnya Tour Merapi, Tebing Breksi, Gardu Padang Kaliurang, pantai Parangtritis, Baron, serta didukung banyaknya desa wisata serta wisata kuliner memiliki daya pemikat bagi para wisatawan, yang memberikan konstribusi ekonomi baik lokal maupun nasional.Namun sejak adanya pandemic covid-19 ini mengalami penurunan pengunjung yang cukup signifikan.

Perhotelan merupakan salah satu aspek yang terkait dengan bisnis pariwisata dan sebagai penunjang dalam kegiatan perkantoran (misalnya sebagai tempat untuk seminar, rapat dan lain-lain). Banyaknya hotel di Yogyakarta merupakan bukti pariwisata dan sangat menjanjikan sebagai bisnis dewasa ini.

Berdasarkan data statistik BPS Yogyakarta pada tahun 2019 jumlah tamu mencapai 9.01 juta, yang terdiri dari 5,24 juta tamu hotel berbintang dan 3,77 juta tamu non berbintang. Jumlah ini mengalami kenaikan 37,98 \% dibandingkan tahun 2018. (BPS, 2020). Namun, sejak Indonesia dilanda wabah Covid-19 menyebabkan merosotnya kunjungan wisman ke Daerah Istimewa Yogyakarta. Tercatat, sejak Maret 2020 kunjungan wisman mengalami penurunan, bahkan mencapai titik terendah pada bulan April, Mei, Juli hingga Desember 2020. Memasuki awal tahun 2021, kunjungan wisman ke Daerah Istimewa Yogyakarta masih nihil seperti kondisi bulan sebelumnya. (BPS Yogyakarta, 2021).Kondisi inilah, hotel menjadi seolah-olah mati suri. hal ini tentu saja tidak diharapkan kita semua

Hotel sebagai bagian yang tak terpisahkan dari bisnis pariwisata di Yogyakarta mengalami penurunan pendapatan yang cukup signifikan. Pada akhir April 2020, diketahui total realisasi dari pajak daerah Kota Yogyakarta mencapai 26,7\% atau Rp 120,4 milyar dari target Rp 451,1 miliar. Pada kuartal pertama 2019, realisasi pajak daerah dapat mencapai 30,44 persen atau senilai Rp 128,05 miliar dari target $\mathrm{Rp}$ 420,7 miliar. Penurunan cukup signifikan ini terjadi pada pajak hotel. (Antara News, 2020)

Untuk itu sangat diperlukan kolaborasi dari berbagai pihak instansi yang terkait, seperti bidang kesehatan, pariwisata, pelaku usaha, untuk mengatasi masalah tersebut. Pandemi yang belum berakhir tentunya dibutuhkan suatu solusi yang tepat sehingga lintas sektoral secara bersama-sama mampu melewati masa sulit ini dengan baik, yang memberikan solusi sektor pariwisata, sehingga apabila wisatawan merasa aman dan nyaman maka dapat meningkat dan jumlah tamu hotelpun akan meningkat juga. Tingkat Penghunian Kamar (TPK) hotel merupakan indikator produktivitasdi sektor usaha jasa akomodasi.

Pemerintah D.I. Yogyakarta melaksanakan tahap uji coba dan melakukan berbagai simulasi guna memastikan kesiapan lokasi-lokasi wisata termasuk hotel, rumah makan, tempat perbelanjaan dan sarana pendukung lainnya. Adanya tim verifikasi dan bidang penegakan hukum yang bertugas untuk menilai sejauh mana kesiapan perangkat-perangkat pendukung khususnya dalam hal penerapan protokol kesehatan dan mengembangkan aplikasi Jogja Pass. Aplikasi ini dapat memantau dan mendata wisatawan yang masuk ke lokasi wisata secara sistematis dan menyesuaikan sesuai kapasitas lokasi wisata yang akan dikunjungi. (Yuswantana, 2020)

Pernyataan Gubernur DI. Yogyakarta, mengenai prinsip keseimbangan aspek ekonomi dan kesehatan kepada pelaku usaha di wilayahnya dalam beradaptasi di tengah pandemi covid-19, dengan cepat direspon oleh para pelaku usaha jasa perhotelan dan restoran sekaligus sebagai motivasi meningkatkan pengunjung khususnya wisatawan menginap di Yogyarta. Sejalan dengan hal tersebut Hotel Cabin Sutomo menyiapkan strategi marketing dalam menyambut pranata baru dalam upaya meningkatkan jumlah tamu hotel di masa pandemic ini.

Strategi merupakan tujuan jangka panjang suatu perusahaan dan penggunaan serta alokasi semua sumber daya yang penting untuk mencapai tujuan tersebut, hal ini sebagaimana dkatakan Chandler (Rangkuti, 2015)

Strategi pemasaran merupakan rencana yang menjabarkan ekspektasi perusahaan akan dampak dari berbagai aktivitas atau program pemasaran terhadap permintaan produk atau lini produknya di pasar sasaran tertentu". (Tjiptono, 2015)

Menurut Sofjan Assauri "strategi pemasaran adalah serangkaian tujuan dan sasaran, kebijakan dan aturan yang memberi arah kepada usaha-usaha pemasaran perusahaan dari waktu ke waktu, pada masing-masing tingkatan dan acuan serta alokasinya, terutama sebagai tanggapan perusahaan dalam menghadapi lingkungan dan keadaan persaingan yang selalu berubah". Persaingan ini terdiri tiga unsur utama, yang meliputi segmentasi (segmentation), penentuan pasar sasaran (targeting) dan penentuan posisi tawaran (positioning).(Raharjo, 2019) 
Faktor-faktor yang mempengaruhi strategi pemasaran (Indrasari,2019) yaitu:

a. Segmentasi pasar,

b. Pemasaran dan prospek,

c. Kebutuhan, keinginan dan permintaan pasar,

d. Produk atau tawaran,

e. Nilai atau kepuasan,

f. Hubungan dan jaringan kerja,

g. Persaingan,

h. Bauran pemasaran.

Bauran Pemasaran (Marketing Mix) menurut Kotler adalah seperangkat alat pemasaran yang digunakan perusahaan untuk terus-menerus mencapai tujuan pemasarannya dalam pasar sasarannya.(Musfar firli, 2020)

a. Produk (Product) : sesuatu yang ditawarkan ke pasar untuk mendapatkan perhatian, pembelian, pemakaian, atau konsumsi yang dapat memenuhi keinginan dan kebutuhan.

b. Harga (Price): menurut Monroe merupakan pengorbanan ekonomis yang dilakukan pelanggan untuk memperoleh produk atau jasa (Lestari, 2018)

Menurut Swastha (mengungkapkan bahwa faktor-faktor tersebut ada pada suatu produk barang/jasa. Faktor tersebut meliputi : (1) Kondisi perekonomian, (2) Penawaran dan permintaan, (3) Elastisitas permintaan, (4) Persaingan, (5) Biaya, (6) Tujuan manager, dan (7) Pengawasan pemerintah.

c. Promosi (Promotion) diartikan suatu upaya atau kegiatan perusahaan dalam mempengaruhi konsumen aktual maupun konsumen potensialagar mereka mau melakukan pembelian terhadap produk yang ditawarkan pada saat ini atau dimasa yang akan datang

d. Saluran Distribusi (Place) merupakan lembagalembaga distributor atau penyalur yang memiliki kegiatan menyalurkan barang-barang atau jasajasa dari produsen ke konsumen.

e. Proses (Process) merupakan variabel yang penting dalam perusahaan jasa yang erat berkaitan dengan aktivitas atau kinerja.

f. Petugas Penyedia Jasa (People) adalah petugas penyedia jasa diharapkan mampu menerjemahkan keinginan pelanggan dalam bentuk pelayanan atau jasa

g. Fasilitas Pendukung secara Fisik (Physical Evidence) merupakan bentuk jasa dapat dilihat dalam keterkaitan antara janji yang telah disampaikan oleh pemberi atau penyedia jasa dengan pelanggan. Jasa yang disampaikan kepada pelanggan tidak dapat dipisahkan dengan fasilitas pendukung secara fisik (physical evidence).

Hotel adalah suatu bentuk usaha yang menggunakan suatu bangunan atau sebagian daripadanya yang khusus disediakan, dimana setiap orang dapat menginap dan makan serta memperoleh pelayanan dan fasilitas-fasilitas lainnya dengan pembayaran. (Samudra, 2016). Hotel merupakan pendukung dari beberapa kegiatan sektor Pariwisata yang menyediakan sarana akomodasi dan tempat pertemuan antara wisatawan dan pelaku industry (Prakoso, 2017)

Usaha Hotel dalam Peraturan Menteri Pariwisata Dan ekonomi adalah adalah usaha penyediaan akomodasi berupa kamar-kamar di dalam suatu bangunan, yang dapat dilengkapi dengan jasa pelayanan makan dan minum, kegiatan hiburan dan/atau fasilitas lainnya secara harian dengan tujuan memperoleh keuntungan.(Indonesia, 2013)

\section{Metode Penelitian}

Pelaksanaan penelitian ini adalah penelitian deskriptif kualitatif. dengan sumber primer dan skunder. Menurut Creswell metode penelitian kualitatif adalah sebagai suatu pendekatan atau penelusuran untuk mengeksplorasi dan memahami suatu gejala sentral.(Raco, 2018). Sumber primer yang digunakan adalah sumber interview, yang dilakukan dengan Supervisor dan bagian front office. Kedua nara sumber tersebut berkompetem untuk memberikan data-data yang diperlukan dalam penelitian ini. Dalam hal ini, sedangkan sumber sekunder yang menggunakan dokumentasi meliputi data dari media berita online, data yang dipublikasi oleh Dinas Pariwisata dan Badan Pusat Statistik, jurnal-jurnal penelitian yang mendukung serta bukubuku literatur

\section{Hasil dan Pembahasan \\ 3.1. Panduan Pelayanan di Hotel menyambut Pranata baru Pariwisata}

Kondisi pandemi yang telah berlangsung lebih dari satu tahun ini berdampak pada sektor pariwisata baik yang berkorelasi langsung maupun tidak langsung. Hal ini diperlukan kolaborasi lintas sektoral antara lain kesehatan, ekonomi, keamanan, baik ditingkat pusat maupun di daerah.

Sebagai tindak lanjut Pergub Nomor 48 2020 tentang Pedoman Penyusunan, Panduan Pelaksanaan Kegiatan Pelayanan Publik dan Perekonomian Masyarakat di Daerah Istimewa Yogyakarta dalam pencegahan dan pengendalian Covid-19, maka diterbitkan buku Pranatan Anyar Plesiran Jogya Panduan Adaptasi Kebiasaan Baru Pariwisata DIY yang merupakan salah satu bentuk respon cepat Dinas Pariwisata DIY dalam mengupayakan kondisi perekonomian di DIY tetap berjalan dengan menerapkan protokol CHS di masa new normal mengacu Keputusan Menteri Kesehatan No HK.01.07/MENKES/328/2020 tentang Panduan Pencegahan dan Pengendalian Covid-19 di tempat kerja perkantoran dan industri dalam mendukung keberlangsungan usaha pada situasi pandemi. Pada 
buku tersebut ada bagian tentang "Panduan Pelayanan Di Hotel", yaitu menjelaskan :

a. Mewajibkan untuk melakukan pendataan tamu yang berkunjung.

b. Menyediakan tempat cuci tangan, sabun, dan hand sanitizer disertai petunjuk pemakaian pada setiap pintu masuk, lift, dan area yang mudah diakses.

c. Menyediakan masker dan face shield sesuai kebutuhan.

d. Menyediakan thermogun.

e. Menyediakan kamar isolasi sebagai antisipasi jika ada kasus Covid-19 saat tamu menginap.

f. Memeriksa kesehatan karyawan secara rutin.

g. Melakukan pembatasan penggunaan kolam renang, karaoke, dan gym station/ fitness center.

h. Memisahkan lokasi untuk drop-off dan pick-up bagi tamu.

i. Melakukan disinfeksi secara berkala minimal tiga hari sekali pada lantai, permukaan pegangan tangga/ eskalator, tombol lift, pegangan pintu, mesin ATM, mesin kasir, alat pembayaran elektronik, metal detector, kaca etalase, area bermain, mushola, toilet, dan fasum lainnya.

j. Sterilisasi kamar setelah tamu check-out.

k. Tidak menyediakan dispenser di area publik atau area yang mudah diakses tamu.

1. Memasang pesan-pesan kesehatan (Cuci Tangan Pakai Sabun/CTPS, etika batuk, pakai masker) pada setiap pintu masuk.

m.Menyarankan tamu yang mengalami demam dengan suhu di atas 37,3 derajat Celcius untuk ke rumah sakit yang dirujuk untuk menangani Covid-19 atau on-call doctor.

n. Mengupayakan AC dalam kamar berfungsi dengan baik dan dibersihkan secara teratur.

o. Mengupayakan toilet dalam keadaan bersih, kering, tidak bau, dan berfungsi dengan baik.

p. Menyediakan tempat sampah dalam keadaan tertutup.

q. Menempel peta lokasi jalur evakuasi dan titik kumpul (untuk antisipasi keadaan darurat).

r. Berkoordinasi dengan dinas kesehatan setempat terkait pengelolaan area publik.

s. Fasilitas parkir harus sesuai jenis kendaraan.

t. Harus ada vallet parking (bagi hotel bintang 4 \& 5).

u. Jalur kendaraan masuk dan keluar harus berbeda.

v. Apabila area parkir berada di basement dan tamu masuk ke hotel dengan menggunakan lift, maka pihak hotel wajib menyediakan sarana cuci tangan/hand sanitizer

w. Petugasas parkir dengan APD (masker dan sarung tangan).(PemdaYogyakarta,2020)

\subsection{Strategi marketing Hotel Cabin Sutomo}

Di masa pandemi Industri perhotelan mengalami mati suri, karena operasional hotel banyak yang ditutup. Hotel sebagai bagian industri jasa akomodasi harus bangkit untuk menompang perekonomian agar semakin kuat. Seiring dengan regulasi yang dikeluarkan pemerintah baik ditingkat pusat maupun daerah guna keseimbangan sektor ekonomi dan kesehatan maka diperlukan strategi marketing.

Sebagai perusahaan pada bidang jasa akomodasi, hotel memberikan kontribusi perekonomian baik secara langsung maupun tidak langsung pada variable-variabel yang terkait dengan hotel. Berdasarkan data dari Dinas Pariwisatam jumlah hotel di Yogyakarta, dapat dilihat pada tabel berikut ini :

Tabel 1. Jumlah Hotel di Yogyakarta

\begin{tabular}{|c|c|c|c|}
\hline Jumlah Hotel & $\begin{array}{l}\text { Tahun } \\
2018\end{array}$ & $\begin{array}{l}\text { Tahun } \\
2019\end{array}$ & $\begin{array}{l}\text { Tahun } \\
2020\end{array}$ \\
\hline Bintang 5 & 9 & 11 & 11 \\
\hline Bintang 4 & 18 & 36 & 42 \\
\hline Bintang 3 & 32 & 61 & 68 \\
\hline Bintang 2 & 24 & 34 & 33 \\
\hline Bintang 1 & 13 & 21 & 18 \\
\hline Non Bintang & 589 & 610 & 618 \\
\hline Jumlah & 589 & 610 & 618 \\
\hline
\end{tabular}

Sumber:(BapedaYogyakarta,n.d.)

Dari tabel 1 jumlah hotel non bintang jumlahnya paling banyak dibandingkan dengan tipe hotel berbintang. Pada tahun 2018 ke 2019 dan tahun 2020 terus mengalami kenaikan. Ini menunjukkan bahwa hotel non bintang memiliki segmen pasar yang luas dengan mengalami kenaikan jumlah dari tahun 2018 ke tahun 2019 dan 2020.

Kondisi pandemi menimbulkan rasa kekuatiran dan ketakutan untuk melakukan pariwisata. Hal ini sebagai salah salah satu faktor turunnya jumlah tamu hotel. Untuk itu hotel perlu memperhatikan penerapan kesehatan dan kebersihan yang baik dalam memberikan pelayanan.

Strategi pemasaran adalah sebuah taktik yang dilakukan perusahaan untuk menawarkan produk atau jasa kepada pelanggan. Setiap perusahaan ingin agar produk atau jasa yang ditawarkannya terjual, maka dari itu perusahaan harus membuat strategi dalam memasarkan produknya agar bisa bersaing dengan perusahaan lain.

Hotel Cabin Sutomo melakukan menyesuaikan diri terhadap perubahan kebutuhan pasar pada masa pandemi, yaitu penyesuaian terhadap beberapa unsur marketing mix yang dijalankan pihak manajemen. Hal yang dilakukan menekankan pada prinsip marketing mix, yaitu product, price, people, promotion dan process.

1. Produk (Product) merupakan setiap tawaran yang dapat memuaskan kebutuhan dan keinginan tamu hotel. Hotel Cabin Sutomo tergolong pada tipe hotel non Bintang, dengan kapasitas tipe kamar Small Shared, Small Privat, Big Shared, Small Privat, Family Shared dan dan Family Privat. Sebagai tipe 
hotel non bintang pada kondisi pandemi covid-19 sekarang ini dimana tingkat daya beli masyarakat turun menjadi salah satu alternatif pilihan akomodasi. Untuk dapat meningkatkan kepercayaan para tamu, sampai saat ini hotel terus meningkatkan upaya penerapan kebersihan dan kesehatan. Seluruh bagian hotel dengan cara dilakukan penyemprotan desinfektan ke bagian-bagian ruangan, memberikan informasi atau petunjuk menjaga jarak/ antrian dan penyediaan hand sinitizer di setiap tempat yang sering terjadi kontak fisik, seperti ruang lobby, resepsionis pintu masuk/keluar ruang pertemuan, pengecekan suhu badan.

2. Harga (Price) sebagai salah satu komponen yang penting. Masa pandemi, dimana daya beli masyarakat turun, maka hotel cabin telah melakukan metode Fixed Fee Pricing yaitu penurunan harga kamar dengan tujuan kamar hotel dapat terjual di masa pandemi. Harga ditawarkan dapat dilihat pada tabel berikut ini :

Tabel 2. Tarif Sewa Kamar

\begin{tabular}{lll}
\hline No & Jenis kamar & Harga \\
\hline 1. & Small Shared & Rp 175.000,- \\
2. & Small Privat & Rp 207.000,- \\
3. & Big Shared & Rp 207.000,- \\
4. & Family Shared & Rp 214.000,- \\
5. & Family Privat. & Rp 231.000,-
\end{tabular}

Sumber : Hotel Cabin, 2021

Dari tabel 2 untuk pemesanan melalui aplikasi yang telah bekerja sama dengan Hotel cabin. Sedangkan untuk walk ins maka calon tamu hotel diberikan pilihan untuk sesuai keperluannya ( short time). Dengan penerapan tarif ini, menjadikan Hotel Cabin tetap menjadi pelanggan

3. People (Karyawan). Peranan sumber daya manusia merupakan bagian unsur penting dalam marketing mix.. Mereka melakukan tugas-tugasnya secara dengan baik dalam memberikan pelayanan tamu hotel mengacu pada SOP hotel Cabin. Dalam kondisi pandemi tindakan preventif dalam kesehatan terus dilakukan dengan pola hidup sehat dan memperhatikan protokol kesehatan dalam menjalankan aktivitas pekerjaannya, dengan kewajibkan penggunaan alat pelindung diri (APD) seperti masker dan face shield (setiap karyawan yang langsung berhadapan dengan tamu).

4. Promosi (Promotion). Pemberlakukan Pembatasan kegiatan Masyarakat (PPKM) di masa pandemi covid-19 ini berimbas cukup berat pada sektor pariwisata, khusus perhotelan, Di sisi lain kondisi pandemi merubah budaya masyarakat mengalami perubahan yang sangat cepat dalam berinteraksi dan bertransaksi. Pemanfaatan teknologi di media sosial meningkat secara signifikan. bahwa penggunaan smartphone untuk mengakses informasi terus meningkat. Hotel cabin menyadari hal ini, untuk meningkatkan promosi melalui digital marketing sebagai strategi marketing. Kegiatan promosi pun dilakukan dengan menggunakan berbagai media seperti facebook, Instagram, whatsapp, telegram, Mi Chat. Selain itu juga promosi bekerjasama dengan tiket.com, booking.com, agonda.com, traveloka, pegipegi.com, tripadvisor, sehingga memudahkan calon tamu hotel untuk melakukan pemesanan. Di samping itu ditunjang oleh bagian Front Office dan yang siap memberikan pelayanan kepada tamu 24 jam yang membutuhkan informasi. Untuk pertanyaanpertanyan yang diajukan via media social, selanjutnya dijawab dengan mengarahkan untuk menghubungi nomor WA untuk mendapat penjelasan lebih rinci. Promosi digital menjadi pilihan yang efekif mengingat kondisi pandemi saat ini dan transformasi budaya masyarakat dalam bersosialisasi dan berkomunikasi menggunakan smartphone.

5. Proses (Process), kegiatan ini diartikan sebagai bentuk pelayanan perusahaan (hotel) kepada tamutamunya. Pelayanan dimulai dari pra, saat dan pasca. Pelayanan pra diberikan pada saat calon tamu (pelanggan) menanyakan pemesanan yang meliputi penjelasan tipe kamar yang tersedia, harga sewa dan fasilitas-fasilitas yang diberikan, baik secara langsung maupun via telepon. Customer service melaksanakan tugasnya dengan ramah, sopan dan menguasai permasalahan yang ditanyakan tamu hotel. Pada saat menginap tamu, akan dilayani dengan baik dari mulai chek in sampai chek out. Adanya pranata baru pariwisata, hotel Cabin melaksanakan protokol kesehatan, misanya penyemprotan disinfektan secara periodik, pengecekan suhu badan bagi karywan maupun tamu yang akan masuk hotel dan penggunaan masker/face shield di area hotel. Sedangakan pelayanan pasca adalah dengan merespon baik masukan dan kritikan dari para tamu yang disampaikan secara langsung ataupun melalui media sosial.

Dari strategi pemasaran yang telah dilakukan, telah memberikan kontribusi yang signifikan.

Tabel 3.

Jumlah tamu hotel tahun 2019-2020

\begin{tabular}{llll}
\hline No & Tahun & Jumlah & ket \\
\hline 1 & 2019 & 8919 & - \\
2 & 2020 & 6983 & Turun 22,7\% \\
\hline
\end{tabular}

sumber : Hotel Cabin, 2021

Data Tabel 3 jumlah kamar hotel yang disewakan sebanyak 30 kamar hotel. Penurunan sebasar 22,7\% tersebut mampu mempertahankan kegiatan operasional hotel, dan selama pandemi tidak terjadi karyawan dirumahkan ataupun dilakukan Pemutusan Hubungan Kerja (PHK).

\section{Kesimpulan}

Kondisi pandemi covid-19 ini, berdampak pada para pelaku usaha sektor pariwisata khususnya usaha perhotelan, yaitu menurunnya jumlah tamu 
hotel. Hotel seolah mati suri. Hal ini harus diantipasi agar hotel tidak mengalami kebangkrutan dan PHK karyawan. Dalam menyambut pranata baru pariwisata Yogyakarta, Hotel Cabin Sutomo mengembangkan strategi marketing sebagai upaya mempertahankan agar hotel dapat operasional mulai dari penekanan efesien pada biaya-biaya operasional, evaluasi strategi dalam pemasaran yang mengacu pada Pemberlakukan Pembatasan Kegiatan Masyarakat (PPKM) dan memperhatikan protokol kesehatan. Kenyamanan, kesehatan dan keselamatan menjadi fokus perhatian hotel Cabin Sutomo.

Mengembangkan digital marketing menjadi skala prioritas dalam melakukan promosi. Untuk tarif sewa kamar, pihak hotel Cabin menyesuaikan dengan kondisi masyarakat di masa pandemi dengan memberikan penurunan tarif sewa dan menggunakan jargon tarif New Normal dengan memberikan pilihan tarif walk in (sesuai kebutuhan tamu) dan tarif sesuai aplikasi pemesanan.secara online. Dengan pilihan tarif yang ditawarkan maka Hotel cabin Sutomo tetap dapat mempertahankan kegiatan operasional di tengah pandemi. Penelitian ini masih menggunakan teknik pengumpulan data wawancara dan dokumentasi, hal ini karena kondisi pandemi yang membatas ruang gerak. Untuk perlu dilakukan penelitian lebih lanjut untuk menggali fenomena lainnya yang nantinya akan menghasilkan hasil temuan baru.

\section{Referensi}

Antara News. (2020, May). Pendapatan daerah Yogyakarta diperkirakan tergerus hingga Rp330 miliar. Antara News. https://www.antaranews.com/berita/1464561/ pendapatan-daerah-yogyakarta-diperkirakantergerus-hingga-rp330-miliar

Bapeda Yogyakarta. (n.d.). Jumlah Hotel Pariwisata.

http://bappeda.jogjaprov.go.id/dataku/data_da sar/index/212-jumlah-hote

BPS Yogyakarta. (2020). Tingkat Penghunian Kamar Hotel Daerah Istimewa Yogyakarta 2019. BPS Yogyakarta. https://yogyakarta.bps.go.id/publication/2020/ 09/10/c276ac09fcce52d940c1ab31/tingkatpenghunian-kamar-hotel-daerah-istimewayogyakarta-2019.html

BPS Yogyakarta. (2021, January). Perkembangan Pariwisata dan Transportasi Udara D.I. Yogyakarta, Januari 2021. Perkembangan Pariwisata dan Transportasi Udara D.I. Yogyakarta, Januari 2021

Indonesia, G. of. (2013). Peraturan Menteri Pariwisata Dan Ekonomi Kreatif Republik Indonesia Nomor PM.53/HM.001/ MPEK/2013 Tentang Standar Usaha Hotel.

Indrasari, D. (2019). Pemasaran dan Kepuasan
Pelanggan. Unitomo Press.

Lestari, S. \& S. H. W. (2018). Determinasi Kepuasaan dan loyalitas Pengguna Jasa Pendidikan Pada Konderfield School Cabang Bekasi Jawa Barat. Akuntasi Dan Manajemen, 15(1).

https://ejournal.stei.ac.id/index.php/JAM/artic le/view/146

Musfar firli, T. (2020). Pemasaran Sebagai Materi Pokok Manajemen Pemasaran. Media Sains Indonesia.

Pemda Yogyakarta. (2020). Panduan Adaptasi Kebiasaan Baru Pariwisata DIY. https://visitingjogja.com/28304/pedomannew-normal-wisata-diy/

Prakoso, P. A. (2017). Front Office Praktis. Administrasi dan Prosedur Kerja (Daryanto (ed.); 1st ed.).

Raco, J. (2018). Metode penelitian kualitatif: jenis, karakteristik dan keunggulannya. https://doi.org/10.31219/osf.io/mfzuj

Raharjo, E. a. (2019). Penguatan Strategi Pemasaran dan Daya Saing UMKM Berbasis Kemitraan Desa Wisata. CV Jakad Publishing.

Rangkuti, F. (2015). TEKNIK MEMBEDAH KASUS BISNIS ANALISIS SWOT. Gramedia Pustaka Utama.

Samudra, A. A. (2016). Perpajakan di Indonesia: Keuangan, Pajak, dan Retribusi Daerah. Rajawali Pers.

Tjiptono, F. (2015). Strategi Pemasaran (4th ed.). Andi.

Yuswantana, B. (2020). Upaya Yogyakarta Dalam Membuka Kembali Sektor Pariwisata. https://corona.jogjaprov.go.id/rilis/berita/102upaya-yogyakarta-dalam-membuka-kembalisektor-pariwisata 